\title{
Characteristics of Absorption Equilibrium with HFC-134a and an Ionic Liquid Pair
}

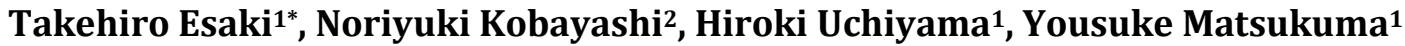 \\ ${ }^{1}$ Department of Chemical Engineering, Faculty of Engineering, Fukuoka University, Fukuoka, Japan \\ ${ }^{2}$ Department of Chemical Systems Engineering, Graduate School of Engineering, Nagoya University, Fukuoka, Japan \\ Email: *tesaki@fukuoka-u.ac.jp
}

How to cite this paper: Esaki, T., Kobayashi, N., Uchiyama, H. and Matsukuma, Y. (2019) Characteristics of Absorption Equilibrium with HFC-134a and an Ionic Liquid Pair. Journal of Materials Science and Chemical Engineering, 7, 65-78. https://doi.org/10.4236/msce.2019.73006

Received: September 12, 2018

Accepted: March 26, 2019

Published: March 29, 2019

Copyright (C) 2019 by author(s) and Scientific Research Publishing Inc. This work is licensed under the Creative Commons Attribution International License (CC BY 4.0)

http://creativecommons.org/licenses/by/4.0/

\begin{abstract}
Cold energy generation systems must be improved to prevent catastrophic climate change. In this study, we focused on an absorption chiller cycle with HFC-134a and an ionic liquid pair as the refrigerant and absorbent, respectively. It was expected that this absorption chiller cycle could generate cold heat below $0^{\circ} \mathrm{C}$. Two liquids were selected and their absorption equilibrium with this pair was evaluated for the absorption chiller cycle. We measured the adsorbed amount at equilibrium with 1-butyl-3-methylimidazolium bis(trifluoromethanesulfonyl)imide [BMIM] [Tf2N] and $\mathrm{N}$-trimethyl-N-butylammonium bis(trifluoromethanesulfonyl)imide [N1113][Tf2N]. The experimental results were reproduced using the nonrandom two liquid (NRTL) model. This analysis model corresponded well in terms of the amount of adsorption at equilibrium with the experimental results. A Duhring diagram was also generated the NRTL model, and the absorption cycle characteristics as a function of temperature were determined. The absorption chiller cycle obtained cold heat at $10^{\circ} \mathrm{C}$ with a regeneration temperature of $70^{\circ} \mathrm{C}$ in addition to generating cold heat below $0^{\circ} \mathrm{C}$.
\end{abstract}

\section{Keywords}

Absorption Chiller Cycle, HFC-134a, Ionic Liquid, Duhring Diagram

\section{Introduction}

Improved efficiency of heat management systems is important for building of a sustainable society. Recently, cold heat energy has seen increasing demand for cooling and frizzing sections in industrial processes. In residential construction, cold energy for air conditioning in the summer is required on a large scale, which only continues to increase [1]. Therefore, it reducing energy consumption 
for the generation cold energy must be met by developing novel technologies. Recently, it has been suggested that the heat-driven chiller and refrigerator could be operated by the heat output of cogeneration, exhausting heat from industrial processes, or solar heat collect systems. As these chillers and refrigerators are commercialized with improved energy efficiency, energy consumption can be reduced for the generation of cold energy. Particularly, absorption chillers feature efficient heat utilization and Figure 1 shows a schematic of absorption chiller operation. Absorption chillers consist of an evaporator, absorber, generator and condenser. The refrigerant vapor from the evaporator is evaporated and introduced into the absorber. The refrigerant vapor is then absorbed in the absorbent and afterwards is moved to the generator while heating. The heat causes the refrigerant gas to be desorbed from the absorbent and condensed in the condenser. The exhaust heat is used as the heat source of the generator. The most common refrigerant/absorbent pairs for absorption chillers are $\mathrm{H}_{2} \mathrm{O} / \mathrm{LiBr}$ aqueous solution [2] and $\mathrm{NH}_{3} / \mathrm{H}_{2} \mathrm{O}$ systems.

Absorption chillers with $\mathrm{H}_{2} \mathrm{O} / \mathrm{LiBr}$ aqueous solution systems have been commercialized and installed as part of building air conditioners. Absorption chillers with $\mathrm{NH}_{3} / \mathrm{H}_{2} \mathrm{O}$ systems are typically used as refrigerators for industrial processes. Although absorption chillers and refrigerator driven heat sources can reduce energy consumption, problems remain in terms of their operation and ability. Absorption chillers with the $\mathrm{H}_{2} \mathrm{O} / \mathrm{LiBr}$ cannot generate cold heat below freezing temperature and the start-up time long time due to the influence of crystallization [3]. Although absorption refrigerator with $\mathrm{NH}_{3} / \mathrm{H}_{2} \mathrm{O}$ can generate cold heat below freezing, the volume of absorption refrigerator required is very large. Thus, flash towers were introduced to ameliorate the problems with the

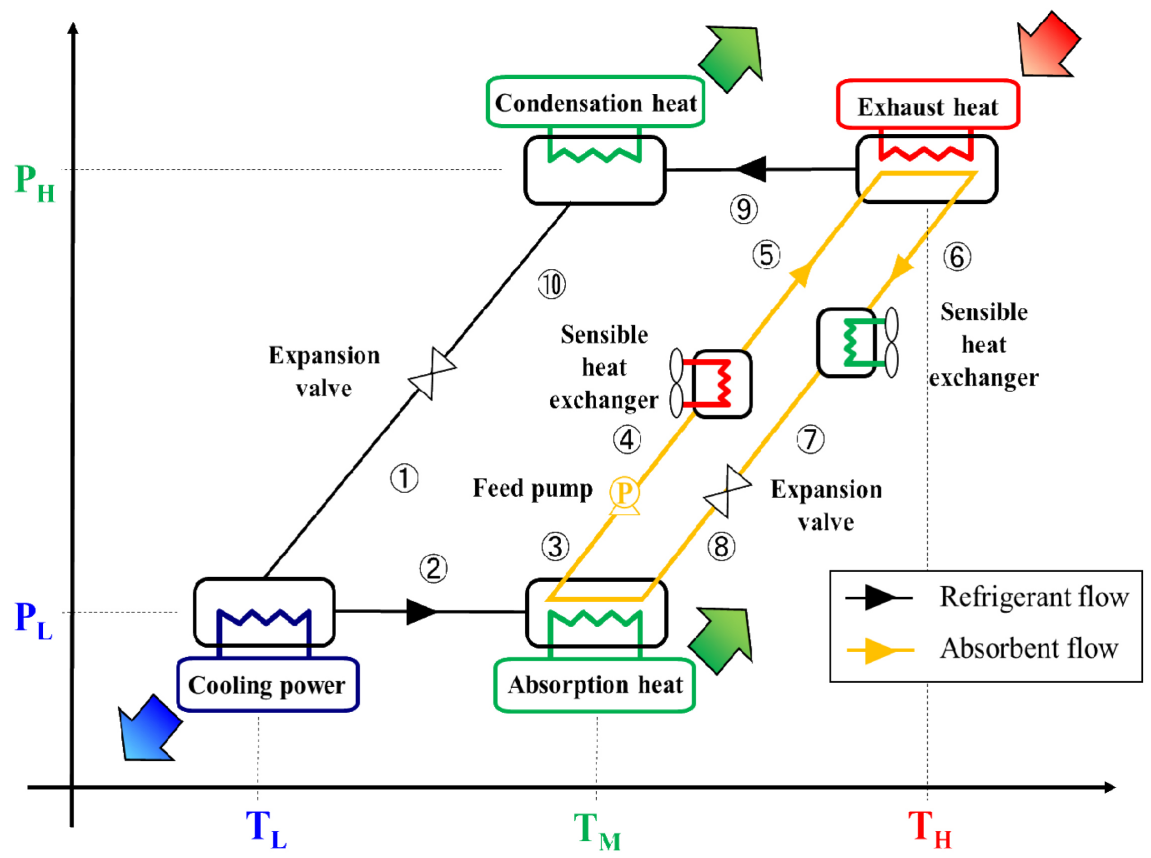

Figure 1. Schematic diagram of the absorption chiller and refrigerator cycle. 
$\mathrm{NH}_{3} / \mathrm{H}_{2} \mathrm{O}$ pair in addition to the refrigerator itself. The material utilized for refrigeration is also limited by the corrosive effects of ammonia dissolved in water.

In this study, we evaluated an absorption chiller with a novel refrigerant/absorbent pair, HFC-134a and ionic liquid. A mechanical type refrigerator was utilized with HFC-134a as the refrigerant.

The ionic liquid consisted of an anion and a cation [4]. Ionic liquids have unique characteristics including very low vapor pressure and wide liquidus range. If an absorption chiller could be operated with an HFC-134a/ionic liquid pair, it could generate cold heat below $0^{\circ} \mathrm{C}$ without the need for a flash tower. As the HFC-134a is used as the refrigerant of the mechanical chiller, it is expected to combine with this absorption chiller and mechanical refrigerator.

In this study, 1-butyl-3-methylimidazolium bis(trifluoromethanesulfonyl)imide [BMIM][Tf2N] and $\mathrm{N}$-trimethyl-N-butylammonium bis(trifluoromethanesulfonyl)imide [N1114][Tf2N] were used as ionic liquid adsorbents and their absorption characteristics in the absorption chiller cycle were evaluated. The dependence of the absorption equilibrium on temperature and pressure with these ionic liquids was also determined along with absorption model correlations with the NRTL model and chiller cycle characteristics using Duhring diagrams.

\section{Experimental Procedure}

\subsection{Experimental Apparatus}

Figure 2 shows the experimental apparatus used to measure the amount of absorption via the volumetric method. This apparatus consisted of an HFC-134a

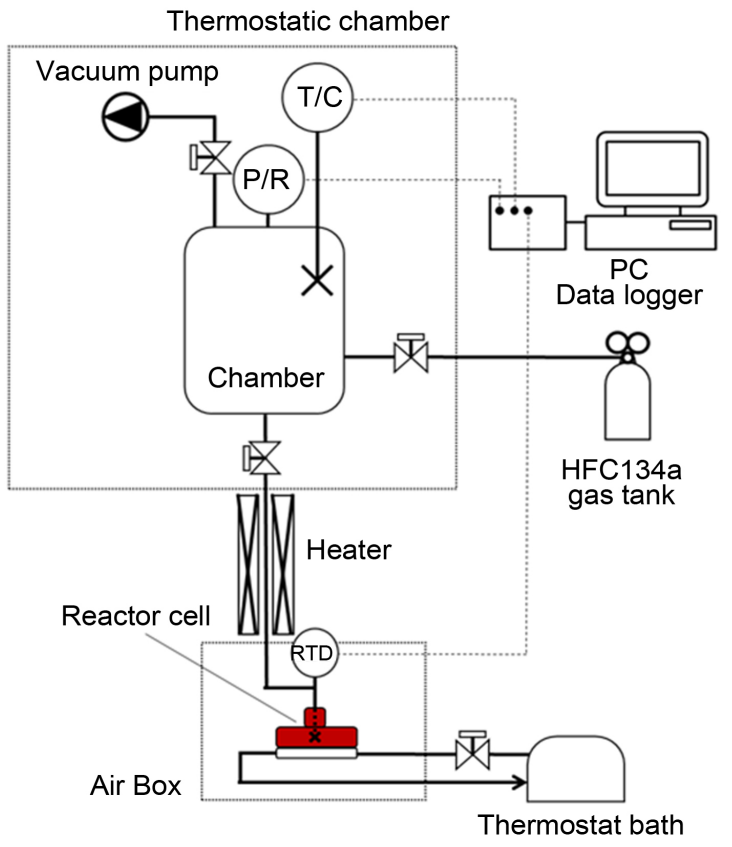

Figure 2. Schematic diagram of the experimental apparatus used for the absorption equilibrium test. 
gas tank, chamber, reactor cell, pressure sensors, and thermocouples. The apparatus was enclosed in a thermostatic box with a chamber volume of $0.74 \times 10^{-3} \mathrm{~m}^{3}$ and reactor cell volume of $0.16 \times 10^{-4} \mathrm{~m}^{3}$. The reactor cell was a flange (Cosmotec corporation, NW50BK) composed of stainless steel. The chamber was equipped with two pressure sensors (SHVG-500KP, Keller corporation, AP-C33, Keyence Japan) which could measure minute pressure changes associated with the absorption by PC. The pressure sensor was selected depending on the measured HFC-134a pressure range. The reaction cell was connected to the heating/cooling system by a thermostat bath and the sample was placed in the reaction cell and measured using Pt resistance temperature sensors.

\subsection{Refrigerant and Absorbent}

The refrigerant used was HFC-134a (1,1,1,2-tetrafluoroethane) with a purity of $>99.7 \%$. The [BMIM][Tf2N] and [N1114][Tf2N] adsorbents were obtained from Wako and Sigma Aldrich Japan, respectively. These absorbents were dried at $343 \mathrm{~K}$ for $2 \mathrm{hr}$ under vacuum and their structures. The property of absorbents is shown in Table 1. Figure 3 shows a photograph of the absorbent in the reactor.

Table 1. Properties of the absorbents used in this study.

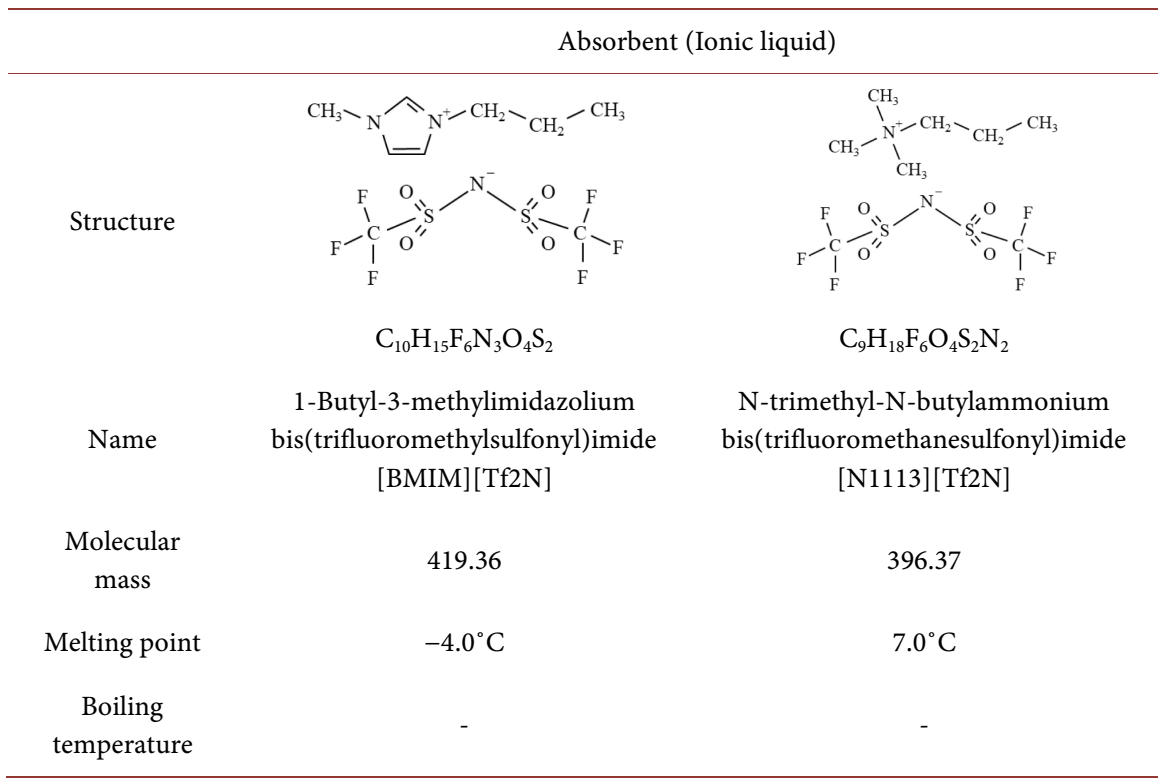

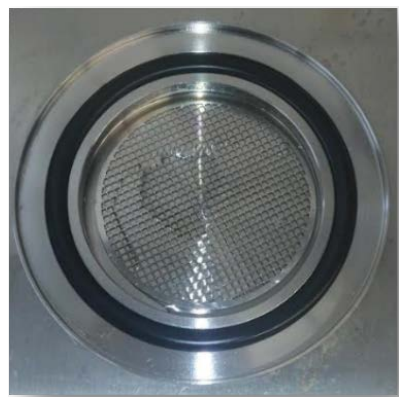

Figure 3. Photograph of the absorbent in the reactor. 
The amount of absorbent used was $2.0 \mathrm{~g}$.

\subsection{Experimental Procedure}

The reactor cell containing the absorbent was connected to the chamber. The experimental equipment was first degassed at $1 \mathrm{kPa}$. To obtain the desired pressure, HFC-134a refrigerant gas was introduced into the chamber and the thermostat bath was set to the desired temperature. Operations involved operating the valves and connecting the reaction cell and the chamber. During absorption, the chamber pressure dropped and was recorded using a PC. When the chamber pressure change reached equilibrium, the amount of HFC-134a used in the absorption was calculated from the pressure change value. The Peng-Robinson equation was used to calculate the weight of the absorbed HFC-134a, and can be expressed as follows:

$$
P=\frac{R_{g} T}{v-b}-\frac{a\left\{1+m\left(1-\sqrt{T / T_{c}}\right)\right\}^{2}}{v^{2}+2 b v-b^{2}}
$$

The absorption extent was calculated as follows:

$$
\begin{aligned}
P_{\text {initial }}-P_{\text {equilibrium }}= & \left(\frac{R_{g} T}{v_{\text {chamber }}-b}-\frac{a\left\{1+m\left(1-\sqrt{T / T_{c}}\right)\right\}^{2}}{v_{\text {chamber }}^{2}+2 b v_{\text {chamber }}-b^{2}}\right) \\
& -\left(\frac{R_{g} T}{v_{\text {equiribrium }}^{2}-b}-\frac{a\left\{1+m\left(1-\sqrt{T / T_{c}}\right)\right\}^{2}}{v_{\text {equiribrium }}^{2}+2 b v_{\text {equiribrium }}-b^{2}}\right) \\
& n_{\text {HFC-134a equiribrium }}=\frac{V_{\text {chamber+cell }}}{v_{\text {equiribrium }}} \\
Z_{\text {HFC-134a absorption }}= & \frac{\left(n_{\text {HFC-134a initial }}-n_{\text {HFC-134a equilibrium }}\right) \cdot M_{\text {HFC-134a }}}{W_{\text {absorbent }}}
\end{aligned}
$$

\section{Results and Discussion}

\subsection{Pressure Change during Absorption Determined by the Volumetric Method}

A representative experimental demonstration is shown in Figure 4. The experiment began when the valve between the reactor and chamber was opened. HFC-134a gas was introduced into the reactor cell and was absorbed by the ionic liquid, as indicated by the decreased chamber pressure. Although the temperature in the reactor cell was initially raised by $0.5^{\circ} \mathrm{C}$, the temperature subsequently decreased and remained at $60^{\circ} \mathrm{C}$ over the entire duration. The pressure decreased as the reaction was allowed to proceed. The equilibrium pressure was defined as that which was maintained for $10 \mathrm{~min}$ and the amount absorbed 


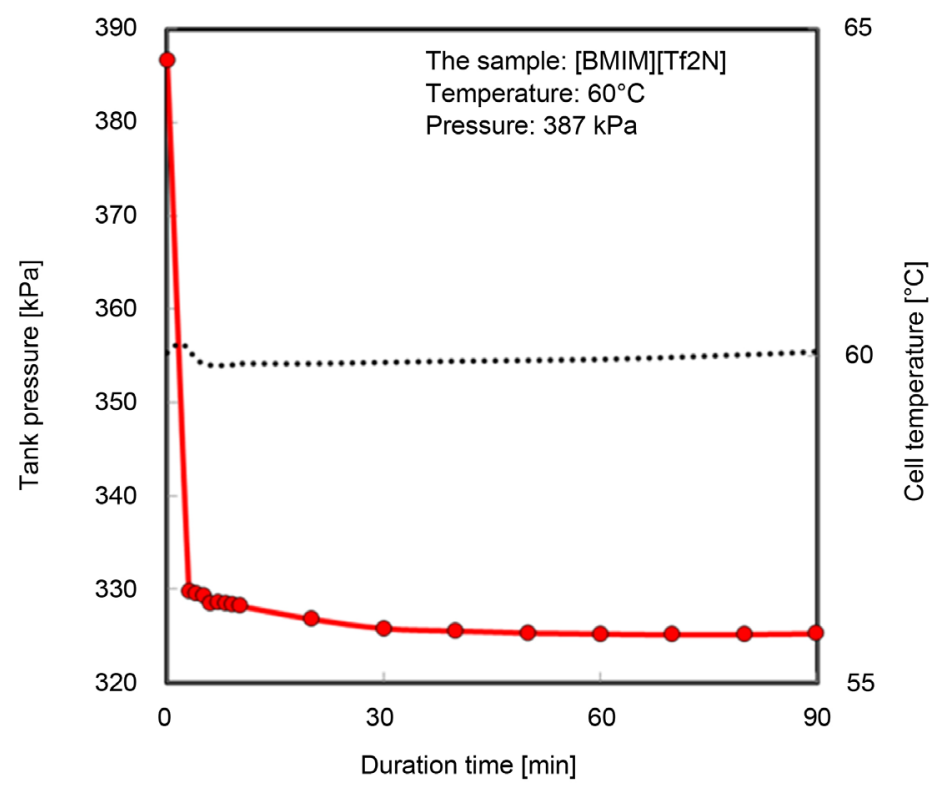

Figure 4. Experimental demonstration of the chamber pressure change.

materials was calculated using the pressure changes with the Peng-Robinson equation.

\subsection{Absorption Equilibrium Model}

Various models for the analysis of experimental absorption of HFC-134a with ionic liquids have been suggested. In this study, the absorption data was analyzed using the non-random two liquid model (NRTL) model. In general, vapor-liquid absorption equilibrium for an $\mathrm{N}$-component system can be expressed by Equation (6),

$$
y_{i} p \Phi_{i}=x_{i} \gamma_{i} p_{i}^{s} \quad(i=1, \cdots, N)
$$

where $y_{i}$ and $x_{i}$ are the vapor phase and liquid phase mole fractions for the ith species, respectively, $P$ is the vapor equilibrium pressure, $P_{i}^{s}$ is the saturated vapor pressure for the ith species, $\Phi_{i}$ is a correction factor for the ith species, and $\gamma_{i}$ is the activity coefficient for the $i$ th species. For the binary system $(N=$ 2 ) of HFC-134a $(R)$ and ionic liquid (IL) mixture system, the ionic liquid has little vapor pressure. Thus, it is reasonable to assume that PILS is 0 on $y_{R}=1$ at the temperatures used in this study. The activity coefficient for HFC-134a can be described by Equation (7):

$$
\gamma_{R}=\frac{P \Phi_{R}}{X_{R} P_{R}^{S}}
$$

In addition, the correction factor, $\Phi_{R}$, for the present case is [5]:

$$
\Phi_{R}=\exp \left[\frac{\left(B_{R}-V_{R}^{L}\right)\left(P-P_{R}^{s}\right)}{R_{g} T}\right]
$$

where the 2nd virial coefficient of species HFC134a, $B_{R}(T)$, was obtained us- 
ing an equation of state program [6] and the molar volume, $V_{R}^{L}$, can be calculated if $T$ is less than the critical temperature, $T_{\mathcal{c}}$ of pure HFC-134a.

Previously, $V_{R}$ was suggested and defined by Equation (9)

$$
V_{R}=\left(1-\alpha_{V}\right) V_{R}^{0}
$$

where $V_{R}^{0}$ is the molar liquid volume of the ionic liquid at temperature $T$ and $\alpha_{V}$ is a unique temperature-independent constant. Here we assumed that $\alpha_{V}=0.594$ [7]. For the isothermal solubility data, the activity coefficients, $\gamma_{R}$, were calculated at each observed $x_{R}$ point. Several activity models are available in the literature [8]. In the NRTL model, $\gamma_{R}$ and $\gamma_{I L}$ are calculated and defined by Equations (10) and (11)

$$
\begin{aligned}
& \gamma_{R}=x_{I L}^{2}\left[\tau_{21}\left(\frac{G_{21}}{x_{R}+x_{I L} G_{21}}\right)^{2}+\frac{\tau_{12} G_{12}}{\left(x_{I L}+x_{R} G_{12}\right)^{2}}\right] \\
& \gamma_{I L}=x_{R}^{2}\left[\tau_{12}\left(\frac{G_{12}}{x_{I L}+x_{R} G_{12}}\right)^{2}+\frac{\tau_{21} G_{21}}{\left(x_{R}+x_{I L} G_{21}\right)^{2}}\right]
\end{aligned}
$$

where $G_{12}$ and $G_{21}$ are defined by the NRTL interaction parameters as described by Equations (12) and (13).

$$
\begin{aligned}
& G_{12}=\exp \left(-\alpha \tau_{12}\right) \\
& G_{21}=\exp \left(-\alpha \tau_{21}\right)
\end{aligned}
$$

where $\alpha$ is the independent unique parameter, assumed to be $\alpha=0.2$ [9], and $\tau_{12}$ and $\tau_{21}$ are adjustable binary interaction parameters using only the temperature dependent terms $\left(\tau_{12}^{0}, \tau_{21}^{0}, \tau_{12}^{1}, \tau_{21}^{1}\right)$. We modeled the parameters as shown in Equations (14) and (15).

$$
\begin{aligned}
& \tau_{12}=\tau_{12}^{0}+\tau_{12}^{1} / T \\
& \tau_{21}=\tau_{21}^{0}+\tau_{21}^{1} / T
\end{aligned}
$$

\subsection{Absorption Extent at Equilibrium}

The amount of absorption equilibrium is summarized in Table 2. The results of the experiment and analysis using the NRTL model with [BMIM][Tf2N] and [N1113][Tf2N] are shown in Figure 5 and Figure 6. Table 3 summarizes the NRTL model parameters for [BMIM][Tf2N] and [N1113][Tf2N] and [BMIM][PF6] used to absorb HFC-134a. From the results, it is clear that the amount of absorption at equilibrium increased, as indicated by the HFC-134a pressure decrease. Figure 7 shows a comparison between the measured and predicted vapor pressure of HFC-134a. In addition, the amount of absorption at equilibrium increased as the HFC134a pressure increased. The error between the experimental and analytical values reached a maximum of $15 \%$ under these conditions. In particular, the pressure sensor exhibits large errors at high pressure $(>500 \mathrm{kPa})$, while the experiment value was well reproduced by the model at low pressures $(<500 \mathrm{kPa})$. Therefore, the type of pressure sensor used, depending on 
Table 2. The amount of absorption at equilibrium with [BMIM][Tf2N] and [N1113][Tf2N] under various experimental conditions.

\begin{tabular}{|c|c|c|c|c|c|}
\hline \multicolumn{3}{|c|}{$[\mathrm{BMIM}][\mathrm{Tf} 2 \mathrm{~N}]$} & \multicolumn{3}{|c|}{$[\mathrm{N} 1113][\mathrm{Tf} 2 \mathrm{~N}]$} \\
\hline$T\left[{ }^{\circ} \mathrm{C}\right]$ & $P[\mathrm{kPa}]$ & $x\left[\mathrm{~g}_{-\mathrm{R}} / \mathrm{g}_{-\mathrm{IL}}\right]$ & $T\left[{ }^{\circ} \mathrm{C}\right]$ & $P[\mathrm{kPa}]$ & $x\left[\mathrm{~g}_{-\mathrm{R}} / \mathrm{g}_{-\mathrm{IL}}\right]$ \\
\hline \multirow{3}{*}{30} & 302.4 & 0.108 & \multirow{4}{*}{40} & 104.3 & 0.013 \\
\hline & 448.5 & 0.229 & & 319.3 & 0.085 \\
\hline & 596.5 & 0.424 & & 465.2 & 0.166 \\
\hline \multirow{3}{*}{40} & 294.3 & 0.054 & & 605.0 & 0.255 \\
\hline & 491.0 & 0.153 & \multirow{4}{*}{50} & 304.5 & 0.060 \\
\hline & 638.2 & 0.277 & & 473.8 & 0.101 \\
\hline \multirow{4}{*}{50} & 304.9 & 0.044 & & 597.7 & 0.145 \\
\hline & 467.9 & 0.094 & & 779.0 & 0.243 \\
\hline & 627.4 & 0.1658 & \multirow{4}{*}{60} & 310.2 & 0.042 \\
\hline & 781.6 & 0.2513 & & 597.4 & 0.112 \\
\hline \multirow{4}{*}{60} & 303.3 & 0.037 & & 790.7 & 0.184 \\
\hline & 460.5 & 0.065 & & 998.0 & 0.278 \\
\hline & 596.0 & 0.097 & \multirow{4}{*}{70} & 301.2 & 0.022 \\
\hline & 770.2 & 0.155 & & 442.0 & 0.043 \\
\hline \multirow{3}{*}{70} & 453.0 & 0.051 & & 802.8 & 0.123 \\
\hline & 804.4 & 0.124 & & 999.0 & 0.173 \\
\hline & 961.9 & 0.169 & \multirow{3}{*}{80} & 304.4 & 0.080 \\
\hline \multirow{3}{*}{80} & 483.4 & 0.041 & & 675.9 & 0.251 \\
\hline & 597.8 & 0.070 & & 1002.4 & 0.326 \\
\hline & 974.4 & 0.131 & \multirow{3}{*}{90} & 475.4 & 0.053 \\
\hline \multirow{2}{*}{90} & 785.9 & 0.071 & & 775.4 & 0.076 \\
\hline & 1006.7 & 0.101 & & 993.3 & 0.090 \\
\hline
\end{tabular}

Table 3. NRTL model parameters for [BMIM][Tf2N], [N1113][Tf2N], and [BMIM][PF6] [9].

\begin{tabular}{ccccc}
\hline & $\tau_{12}^{0}$ & $\tau_{21}^{0}$ & $\tau_{12}^{1}$ & $\tau_{21}^{1}$ \\
\hline$[$ BMIM][Tf2N] & -1.550 & 809.5 & 0 & 0 \\
{$[$ N1113][Tf2N] } & $1.24 \times 10^{-6}$ & 256.5 & $4.35 \times 10^{-7}$ & $0.86 \times 10^{-3}$ \\
{$[$ BMIM][PF6] } & -3.001 & 1699.2 & 2.51 & -1000 \\
\hline
\end{tabular}

the experimental pressure, strongly influenced the experimental error value.

Different ionic liquids were prepared to evaluate the effects of ion structure on absorption equilibrium. Figure 8 shows the amount of absorption at equilibrium at $50^{\circ} \mathrm{C}$ with three ionic liquids. The [BMIM][Tf2N] and [N1113][Tf2N] data was obtained from this study, and that of [BMIM][PF6] was from the literature [9]. Figure 8 shows that the amount of absorption at equilibrium was equivalent for all three ionic liquids.

The absorption heat value was calculated using the amount of absorption 


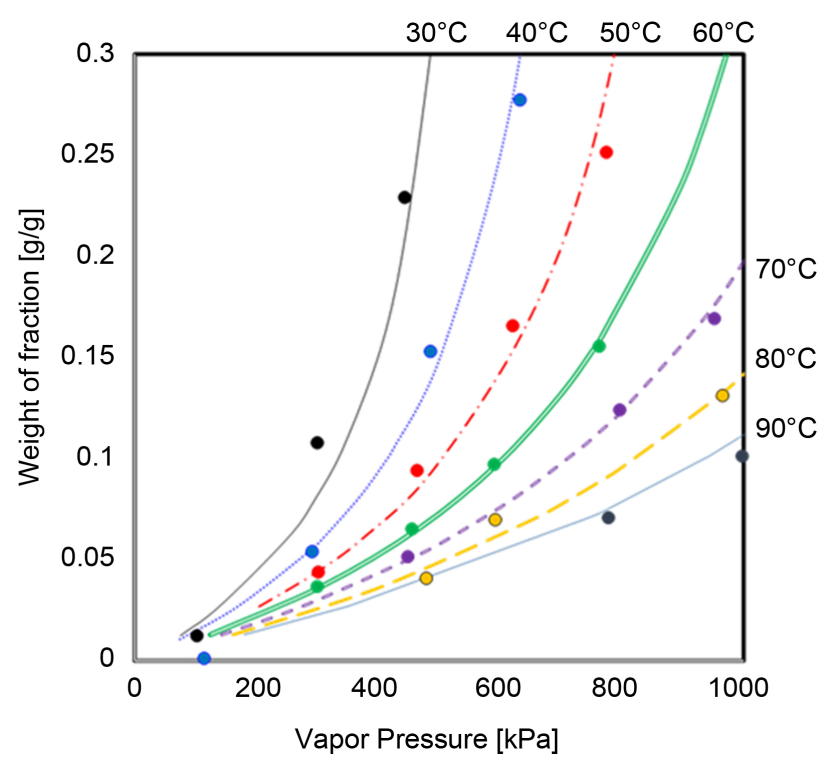

Figure 5. Representative temperature variation of the weight fraction for different HFC-134a pressures with [BMIM] $\left[\mathrm{Tf}_{2} \mathrm{~N}\right]$.

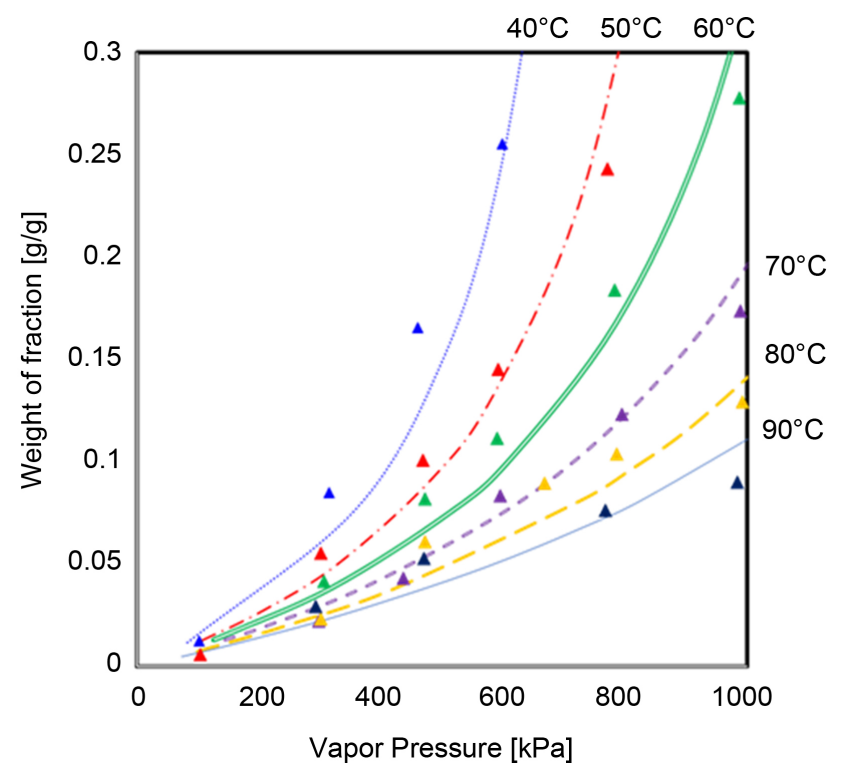

Figure 6. Representative temperature variation of the weight fraction for different HFC-134a pressure with [N1113] $\left[\mathrm{Tf}_{2} \mathrm{~N}\right]$.

obtained in the analysis using the Clausius-Clapeyron equation, as described by Equation (16):

$$
\ln \left(\frac{P_{1}}{P_{2}}\right)=-\frac{\Delta H_{a b}}{R_{g}}\left(\frac{1}{T_{2}}-\frac{1}{T_{1}}\right)
$$

When the same amount of absorption was obtained at different temperatures and pressures, Equation (16) held true. From the calculation results, the absorption heat value was different depending on the amount of absorption and temperature conditions. The obtained values were $1.1-1.5$ times the latent heat at 


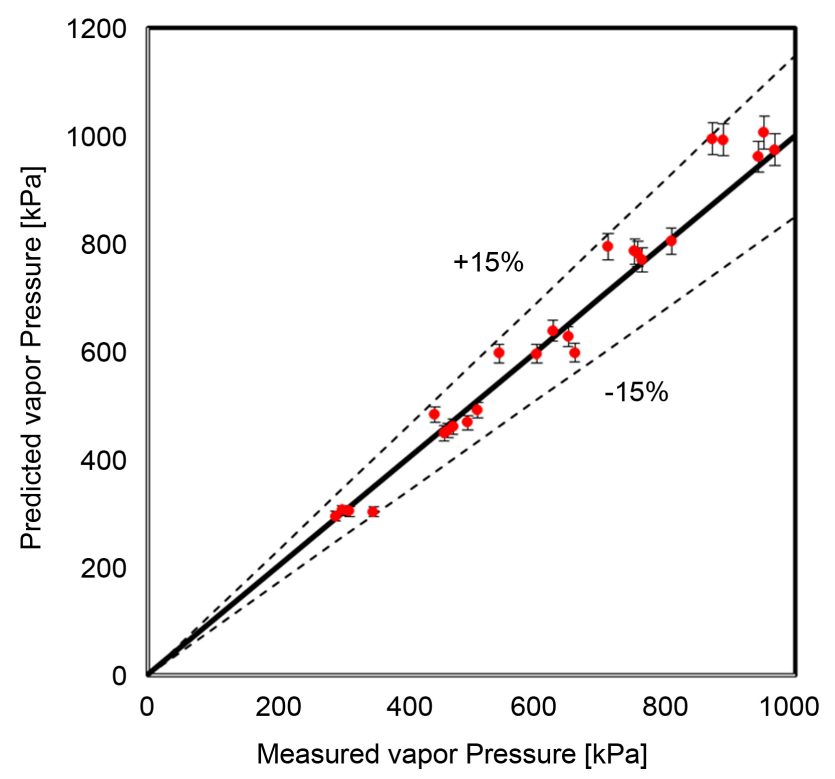

Figure 7. Comparison between the measured and predicted vapor pressures of the refrigerants in the ionic liquid mixture using the NRTL model.

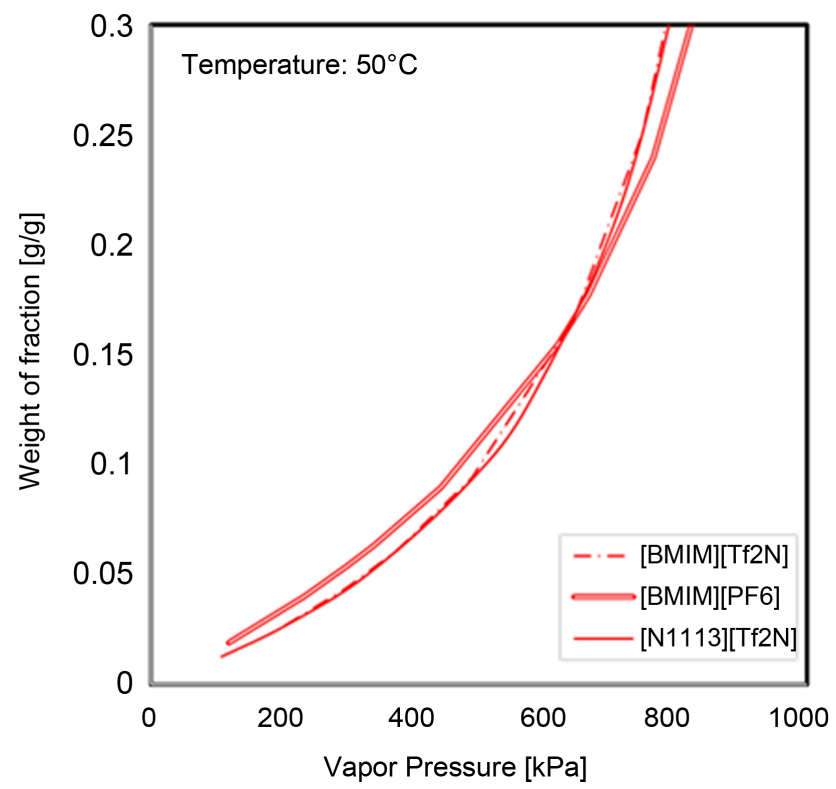

Figure 8. Representative absorbent variation for the weight fraction for different HFC-134a pressures with the NRTL model.

each temperature.

\subsection{Some Common Mistakes}

The characteristics of the absorption chiller and refrigerator cycle was investigated using the Duhring diagram of absorption solubility. We created Duhring diagrams of the absorption equilibrium obtained experimentally. The absorption relationship was expressed in terms of weight fraction in this diagram and Table 4 
lists the concentration weight of fraction at each temperature and pressure. As the evaporator temperature decreased, the concentration of adsorbent also decreased. Figure 9 shows the Duhring diagram for [BMIM][Tf2N] which was used to evaluate the effect of regeneration temperature on the absorption weight fraction. The evaporator, absorber, and condenser were set to $10^{\circ} \mathrm{C}, 30^{\circ} \mathrm{C}$, and $30^{\circ} \mathrm{C}$, respectively. The absorption weight was $13.9 \mathrm{wt} \%$ on the evaporator and absorber under these temperature conditions. The weight of desorption was 6.8 , 8.1, and $10.2 \mathrm{wt} \%$ at $90^{\circ} \mathrm{C}, 80^{\circ} \mathrm{C}$, and $70^{\circ} \mathrm{C}$, respectively. A significant difference in the absorption and desorption weights could be obtained under these temperature conditions. The absorption chiller could be operated with highest efficiency at $70^{\circ} \mathrm{C}$ and Figure 10 shows the effect of the evaporator set to $10^{\circ} \mathrm{C}, 5^{\circ} \mathrm{C}$, and $0^{\circ} \mathrm{C}$, with the generation temperature set to $90^{\circ} \mathrm{C}$. From Figure 10, an effective absorption chiller cycle was obtained with freezing heat at the evaporator at $0^{\circ} \mathrm{C}$, but the difference between absorption and desorption weight fraction was minimal. It is likely that a large volume of absorbent must be circulated to obtain significant amounts of freezing heat compared to other temperature conditions.

Table 4. Lists the concentration weight of fraction at each temperature and pressure.

\begin{tabular}{ccccc}
\hline & & \multicolumn{3}{c}{ Generator temperature } \\
\cline { 3 - 5 } & & 70 & 80 & 90 \\
\hline $\begin{array}{c}\text { Evaporator } \\
\text { temperature }\end{array}$ & 0 & - & - & 0.33 \\
& 5 & - & 1.6 & 3.1 \\
& 10 & 11.2 & 5.7 & 7.1 \\
\hline
\end{tabular}

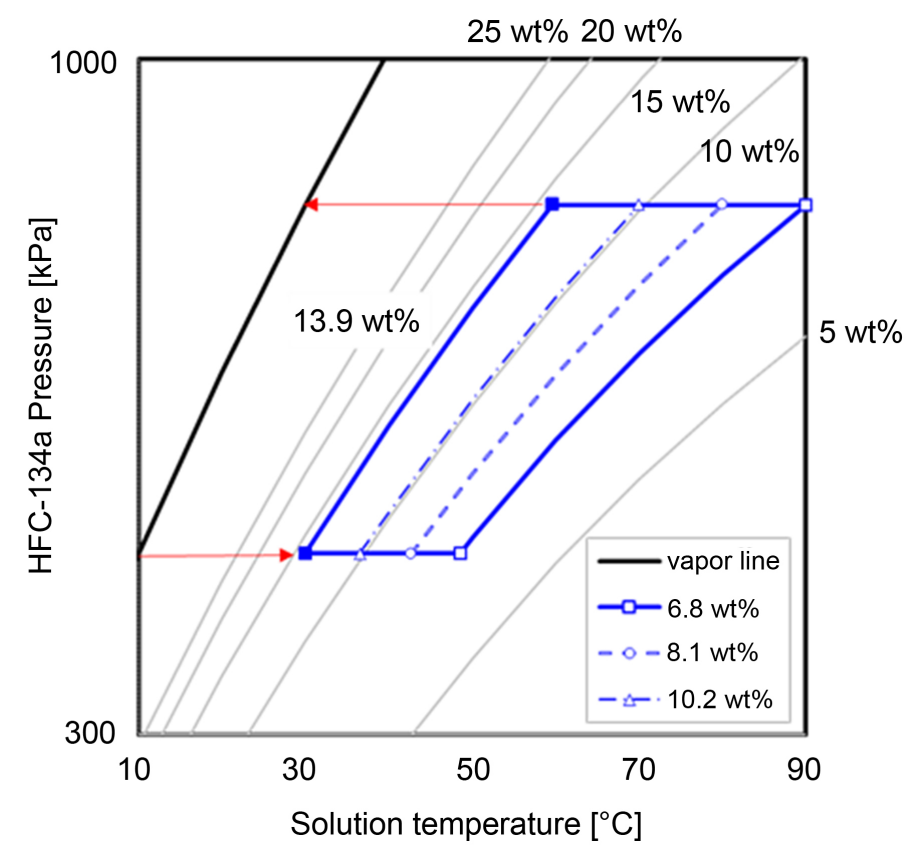

Figure 9. The Duhring diagram of HFC-134a and [BMIM] $\left[\mathrm{Tf}_{2} \mathrm{~N}\right]$ for different regeneration temperatures. 


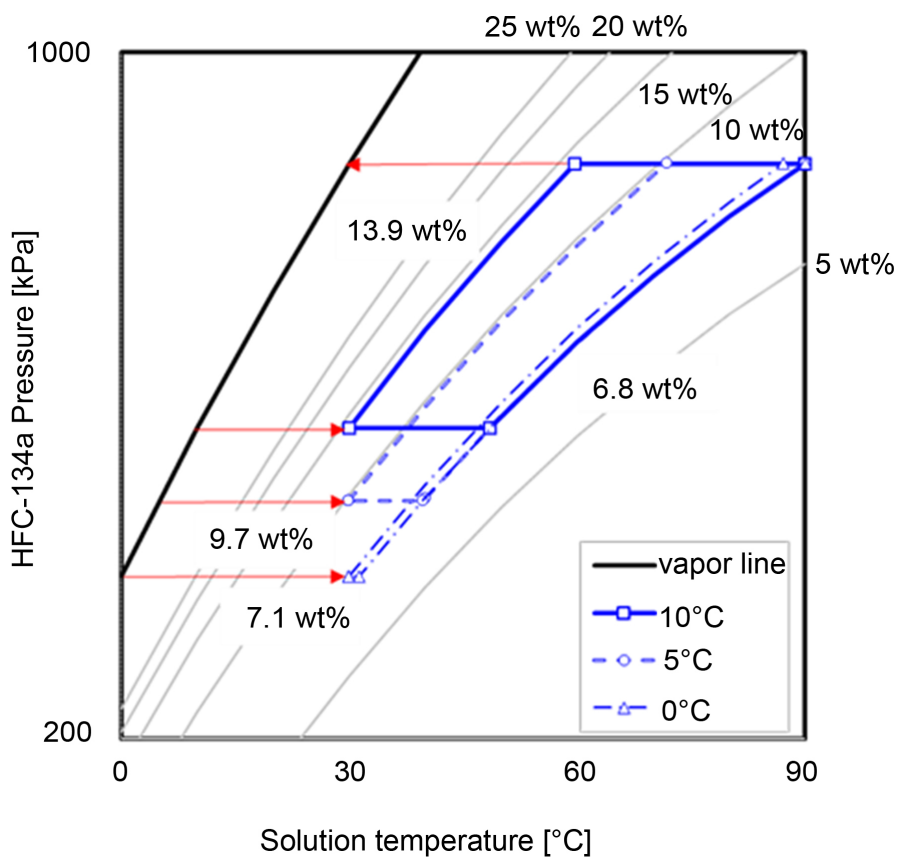

Figure 10. The Duhring diagram of HFC-134a and [BMIM] $\left[\mathrm{Tf}_{2} \mathrm{~N}\right]$ for different evaporator temperatures.

\section{Conclusions}

In this study, absorption chiller cycle characteristics were evaluated for a novel refrigerant and absorbent. HFC-134a was selected as a refrigerant and 1-butyl-3-methylimidazolium bis(trifluoromethanesulfonyl)imide [BMIM][Tf2N] and N-trimethyl-N-butylammonium bis(trifluoromethanesulfonyl)imide [N1113][Tf2N] as absorbents. The major conclusions can be summarized as follows:

1) The amount of absorption at equilibrium of the [BMIM][Tf2N] and [N1113][Tf2N] systems was measured using the volumetric method. The amount of absorption at equilibrium was affected by absorption temperature and HFC-134a pressure. The experimental results could be accurately reproduced by the NRTL model using suitable NRTL model parameters.

2) Duhring diagrams were generated for the HFC-134a and [BMIM][Tf2N] pair. Freezing cold heat could be successfully generated at a regeneration temperature of $90^{\circ} \mathrm{C}$.

\section{Conflicts of Interest}

The authors declare no conflicts of interest regarding the publication of this paper.

\section{References}

[1] U.S. Energy Information Administration (2017) International Energy Outlook. https://www.eia.gov/outlooks/ieo/

[2] Sabbagh, A.A. and Gómez, J.M. (2018) Optimal Control of Single Stage LiBr/Water 
Absorption Chiller. International Journal of Refrigeration, 92, 1-9. https://doi.org/10.1016/j.ijrefrig.2018.05.007

[3] Ihtsham-ul-Haq Gilani, S. and Ahmed, M.S.M.S. (2015) Crystallization Detection for Double-Effect $\mathrm{LiBr}-\mathrm{H}_{2} \mathrm{O}$ Steam Absorption Chiller. Energy Procedia, 75, 1522-1528. https://doi.org/10.1016/j.egypro.2015.07.304

[4] Minea, A.A. and Murshed, S.M.S. (2018) A Review on Development of Ionic Liquid Based Nanofluids and Their Heat Transfer Behavior. Renewable and Sustainable Energy Reviews, 91, 584-599. https://doi.org/10.1016/j.rser.2018.04.021

[5] Dong, L., Zheng, D.X. and Wu, X.H. (2012) Working Pair Selection of Compression and Absorption Hybrid Cycles through Predicting the Activity Coefficients of Hydrofluorocarbon + Ionic Liquid Systems by the UNIFAC Model. Industrial \& Chemistry Research, 51, 4741-4747. ttps://doi.org/10.1021/ie202029d

[6] Yokozeki, A., Sato, H. and Watanabe, K. (1997) Ideal-Gas Heat Capacities and Virial Coefficients of HFC Refrigerants. International Journal of Thermophysics, 19, 89-127. https://doi.org/10.1023/a:1021499018749

[7] Shiflett, M.B. and Yokozeki, A. (2006) Solubility and Diffusivity of Hydrofluorocarbons in Room-Temperature Ionic Liquids. AIChE Journal, 52, 1205-1219. https://doi.org/10.1002/aic.10685

[8] Walas, S.M. (1985) Phase Equilibria in Chemical Engineering. Butterworth, Boston.

[9] Shiflett, M.B., Harmer, M.A., Junk, C.P. and Yokozeki, A. (2006) Solubility and Diffusivity of 1,1,1,2-Tetrafluoroethane in Room-Temperature Ionic Liquids. Fluid Phase Equilibria, 242, 220-232. https://doi.org/10.1016/j.fluid.2006.01.026 
Nomenclature

\begin{tabular}{|c|c|c|c|}
\hline \multicolumn{2}{|r|}{ Nomenclature } & \multicolumn{2}{|c|}{ Subscripts } \\
\hline$P$ & Pressure $[\mathrm{kPa}]$ & initial & initial \\
\hline$R_{g}$ & Gas constant $\left[\mathrm{J} \cdot \mathrm{mol}^{-1} \cdot{ }^{\circ} \mathrm{C}^{-1}\right]$ & equilibriun & n equilibrium \\
\hline$v$ & Molar volume $\left[\mathrm{m}^{3} \cdot \mathrm{mol}^{-1}\right]$ & chamber & chamber \\
\hline$\Delta H_{a b}$ & Absorption heat $\left[\mathrm{kJ} \cdot \mathrm{mol}^{-1}\right]$ & cell & reactor dell \\
\hline$T$ & Temperature $\left[{ }^{\circ} \mathrm{C}\right]$ & absorption & absorption \\
\hline$T_{C}$ & Critical temperature $\left[{ }^{\circ} \mathrm{C}\right]$ & HFC-134a & HFC-134a \\
\hline$z$ & Weight of fraction $\left[\mathrm{g}_{\text {-refrigerant }} / \mathrm{g}_{\text {-absorbent }}\right]$ & absorbent & absorbent \\
\hline$n$ & Molar quantity [mol] & $\mathrm{R}$ & refrigerant \\
\hline$M$ & Molecular weight $\left[\mathrm{kg} \cdot \mathrm{mol}^{-1}\right]$ & IL & ionic liquid \\
\hline$W$ & Weight $[\mathrm{g}]$ & & \\
\hline$V$ & Volume $\left[\mathrm{m}^{3}\right]$ & & \\
\hline$\Phi$ & Correction factor $[-]$ & & \\
\hline$\gamma$ & Activity coefficient [-] & & \\
\hline$P_{i}^{s}$ & Saturated vapor pressure $[\mathrm{kPa}]$ & & \\
\hline$B$ & 2nd virial coefficient $\left[\mathrm{m}^{3} \cdot \mathrm{mol}^{-1}\right]$ & & \\
\hline$\alpha$ & Unique temperature-independent constant [-] & & \\
\hline$y$ & Vapor phase mole fraction $[-]$ & & \\
\hline$x$ & Liquid phase mole fraction $[-]$ & & \\
\hline$\tau, G$ & NRTL model parameters [-] & & \\
\hline$a, b, m$ & Peng-Robinson equation parameters [-] & & \\
\hline$V_{R}^{L}$ & Molar liquid volume $\left[\mathrm{m}^{3} \cdot \mathrm{mol}^{-1}\right]$ & & \\
\hline
\end{tabular}

